\title{
Isolation, Purification, and Biological Activity of a Phytotoxin Produced by Stemphylium solani
}

\author{
Lu Zheng, Rujing Lv, Junbin Huang, and Daohong Jiang, The Key Lab of Plant Pathology of Hubei Province, \\ Huazhong Agricultural University, Wuhan, 430070, China; and Tom Hsiang, School of Environmental Sciences, \\ University of Guelph, Guelph, ON N1G 2W1, Canada
}

\begin{abstract}
Zheng, L., Lv, R., Huang, J., Jiang, D., and Hsiang, T. 2010. Isolation, purification, and biological activity of a phytotoxin produced by Stemphylium solani. Plant Dis. 94:1231-1237.

Stemphylium solani, the causal agent of leaf blight of garlic (Allium sativum), produced phytotoxic metabolites in culture. A non-host-specific phytotoxin from culture filtrate of $S$. solani isolate DY-5, named SS-toxin, was extracted by ethyl acetate, isolated by bioassay-guided thin layer chromatography on silica gel, and purified by preparative liquid chromatography. SS-toxin produced necrotic lesions on detached garlic leaves, similar to that caused by $S$. solani. When wounded leaves were each treated with a 10- $\mu$ l droplet of toxin, Changbanpo, a garlic cultivar susceptible to leaf blight, showed necrotic lesions at $11 \mu \mathrm{g} / \mathrm{ml}$ toxin, while a resistant cultivar, Qingganruanye, showed symptoms at $44 \mu \mathrm{g} / \mathrm{ml}$. The effective doses causing 50\% inhibition $\left(\mathrm{EC}_{50}\right.$ values) of root growth and shoot elongation of the susceptible cultivar were 64.9 and $178.5 \mu \mathrm{g} / \mathrm{ml}$, respectively. The SS-toxin significantly inhibited mitotic activity of root tip cells of the susceptible cultivar from $22 \mu \mathrm{g} / \mathrm{ml}$ and higher causing an abnormally high frequency of cells in interphase. Concentrations over $50 \mu \mathrm{g} / \mathrm{ml}$ of SS-toxin were found to be significantly toxic to total chlorophyll, both chlorophyll a and b, of the susceptible cultivar. The plasma membranecell wall interface, nuclear membranes, mitochondria, and chloroplasts were affected by SStoxin in susceptible leaf cells. This is the first report of the purification and testing of a phytotoxin produced by $S$. solani.
\end{abstract}

Garlic leaf blight caused by Stemphylium solani is a serious disease in vegetable-growing areas of China (28). Symptoms of the disease start as small white spots ( 1 to $3 \mathrm{~mm}$ ) enlarging to elongated purple necrotic lesions along the vein, followed by blighting of the leaf tips. Similar symptoms were produced by culture filtrates of $S$. solani, and a strong correlation was also found between garlic cultivar sensitivity to $S$. solani and sensitivity to $S$. solani culture filtrates (29), suggesting the possible involvement of phytotoxins in lesion symptom development. We recently found that $S$. solani isolated from garlic produced toxins that were non-host-specific, and caused symptoms normally associated with leaf blight on a variety of plants (29).

The phytotoxic metabolites of several species of Stemphylium have been isolated or structurally characterized. The phytotoxins produced by $S$. botryosum include stemphyltoxin (I-IV), stemphyperylenol (3), stemphylin (4), stemphyloxin (I, II) $(5,6,16)$, and stemphol (22). Stemphylone/

Corresponding authors: J. Huang and T. Hsiang

E-mail: junbinhuang@mail.hzau.edu.cn

and thsiang@uoguelph.ca

Accepted for publication 18 June 2010.

doi:10.1094/PDIS-03-10-0183

(C) 2010 The American Phytopathological Society radicinin $(9,11)$ and pyrenophorin (10) were found with $S$. radicinum, and stemphone (12) was found with $S$. sarcinaeforme. However, chemical synthesis of the aglycone from stemphylin has shown that its originally proposed structure requires revision $(23,25)$. The partial chemical structure of SV-toxin produced by $S$. vesicarium is a benzaldehyde ring attached to some unknown groups (18). All these structurally characterized toxins are low molecular weight secondary compounds with diverse chemical structures. However, the toxin(s) secreted by $S$. solani has not yet been structurally elucidated. Culture filtrates of $S$. solani isolated from cotton were found to contain host-specific toxins that were proved to be nonproteinaceous (17). Preliminary chemical characterization of the SS-toxin produced by S. solani showed it to be a quinone compound containing phenolic hydroxyl groups, and the UV and IR spectra of SS-toxin are both different from those of other Stemphylium metabolites described above (30).

The objectives of this study were to purify the major phytotoxin related to a virulent $S$. solani isolate, and to assess biological activities of this phytotoxin.

\section{MATERIALS AND METHODS}

Fungal cultures and toxin production. Cultures of a virulent isolate (DY-5) of $S$. solani (28) were grown on potato sucrose agar (PSA) plates at $25^{\circ} \mathrm{C}$ for 7 days and then stored at $4^{\circ} \mathrm{C}$. For toxin production, four 6-cm-diameter mycelial plugs from PSA cultures were transferred into a 500$\mathrm{ml}$ flask containing $200 \mathrm{ml}$ of potato sucrose broth (PSB), potato dextrose broth (PDB), King's B broth (KB), Czapek's medium (Czapek), Richard's medium (Richard), $\mathrm{V}_{8}$ medium $\left(\mathrm{V}_{8}\right)$, or Fries' basic medium (Fries). The cultures were then incubated at $25^{\circ} \mathrm{C}$ on a rotary shaker $(150$ rpm) under continuous diffused light for 21 days. Culture filtrates were obtained by passing the liquid through four layers of cheesecloth and Whatman no. 1 filter paper. Unless otherwise stated, PSB culture filtrate was used for all subsequent tests.

Leaf necrosis assay. The biological activities of crude and processed extracts were determined by leaf necrosis assay on susceptible garlic leaves (cv. Changbanpo), with some tests on a resistant cultivar, Qingganruanye, which rarely shows disease in the field. The methods follow Zheng et al. (29). Briefly, for each treatment, 10 leaves at the three-leaf stage were detached, abaxial surface lightly wounded, and a 30- $\mu$ l solution applied to the wound site. Leaves were then incubated in a moist chamber at $25^{\circ} \mathrm{C}$ for 3 days, and the lesion area around each wound was assessed. Each bioassay was repeated three times, and leaves treated with sterile distilled water and noninoculated media served as controls.

Bioactivity of soluble macromolecular compounds from culture filtrates. An equal volume of methanol or acetone was added to $200 \mathrm{ml}$ of culture filtrate and stored overnight at $4^{\circ} \mathrm{C}$. Precipitates were collected by centrifugation at $8,000 \mathrm{rpm}$ for $10 \mathrm{~min}$. The precipitates were then dissolved in $200 \mathrm{ml}$ of sterile distilled water, and bioactivity was assessed by leaf necrosis assay as above. The supernatant was evaporated to dryness at $50^{\circ} \mathrm{C}$, dissolved in $200 \mathrm{ml}$ of sterile distilled water, and also bioassayed as above.

Adsorption of toxins by active carbon from culture filtrates. Following the methods of Vidhyasekaran et al. (26), activated carbon at $60 \mathrm{~g} / \mathrm{liter}$ was placed into culture filtrate $(200 \mathrm{ml})$, chilled at $4^{\circ} \mathrm{C}$ for $1 \mathrm{~h}$, and then filtered through Whatman no. 1 filter paper. The filtrate was then evaporated to dryness at $50^{\circ} \mathrm{C}$, dissolved in 200 $\mathrm{ml}$ of sterile distilled water, and bioassayed as above. The carbon remaining in the filter paper was washed with $200 \mathrm{ml}$ of hot 
methanol $\left(50^{\circ} \mathrm{C}\right)$ and shaken $(80 \mathrm{rpm})$ for $20 \mathrm{~min}$. The methanol was then evaporated at $50^{\circ} \mathrm{C}$, and the residue was dissolved in $200 \mathrm{ml}$ of sterile distilled water and bioassayed as above.

Solvent extraction. The extraction procedure followed Vikrant et al. (27) with minor modifications. Culture filtrate (50 $\mathrm{ml}$ ) was extracted three times with half volumes of petroleum ether, cyclohexane, carbon tetrachloride, ether, benzene, ethyl acetate, or chloroform using a separatory funnel. Both water and solvent fractions were evaporated to dryness at $50^{\circ} \mathrm{C}$. The residues were dissolved in $50 \mathrm{ml}$ of sterile distilled water, and their toxicity was measured using leaf necrosis assay. Sterile distilled water and culture filtrate served as controls.

Effect of heat treatment on toxin activity. To determine the thermostability of toxins, culture filtrates were subjected to $60,70,80,90,100$, or $121^{\circ} \mathrm{C}$ for 10,30 , or $60 \mathrm{~min}$ in a water bath or autoclave, and bioassayed as above. Sterile distilled water and untreated culture filtrate served as controls.

Isolation of phytotoxin from culture filtrates. After methanol precipitation, filtrate from a 21-day-old culture was extracted three times with half-volume ethyl acetate, and evaporated to dryness at $50^{\circ} \mathrm{C}$. A yellow-brown residue was obtained and dissolved in $10 \mathrm{ml}$ of hot methanol for analysis by thin-layer chromatograph (TLC). Preparative analytical TLC plates coated with a GF-254 fluorescent silica gel $(5 \times 20 \mathrm{~cm}$, Qingdao, China) and spotted with samples were developed separately in solvent systems containing (i) normal butanol/acetone/water $(6: 1: 3, \quad \mathrm{vol} / \mathrm{vol} / \mathrm{vol})$, (ii) chloroform/methanol/water $\quad(6: 3: 1$, $\mathrm{vol} / \mathrm{vol} / \mathrm{vol}$ ), (iii) chloroform/water/formic acid (6:3:1, vol/vol/vol), (iv) normal butanol/acetic acid/water (8:2:1, vol/vol/vol), (v) normal butanol/cyclohexane/methanol (15:5:1, vol/vol/vol), (vi) ethyl acetate/petroleum ether $(2: 1, \mathrm{vol} / \mathrm{vol})$, (vii) ethyl acetate/hexane $(8: 1, \mathrm{vol} / \mathrm{vol})$, (viii) normal butanol/hexane/methanol (15:5:1, $\mathrm{vol} / \mathrm{vol} / \mathrm{vol}$ ), or (ix) ethyl acetate/petroleum ether/methanol (4:1:0.35, vol/vol/vol).

TLC plates using the last solvent mentioned above were marked under ultraviolet (UV) light at $254 \mathrm{~nm}$, and each band was then carefully scraped off the plate. The scrapings were dissolved in ethylacetate, filtered through Whatman no. 1 filter paper, and centrifuged at 8,000 rpm for $10 \mathrm{~min}$. The ethyl acetate filtrate was dried with a rotary evaporator at $50^{\circ} \mathrm{C}$. A portion of each residue from separate TLC bands was dissolved to $5 \%$ (wt/vol) in sterile distilled water and subjected to leaf necrosis assay. Several fractions showed toxicity in the leaf assay, but the one showing highest toxicity was used subsequently for purification.

Purification of phytotoxin. The biologically active compound selected from the most active fraction on TLC plates was dissolved in methanol, filtered, and then subjected to analytical high-performance liquid chromatography (HPLC) and preparative liquid chromatography (LC). Analytical HPLC was carried out with an Agilent 1100 series HPLC system (Agilent, Palo Alto, USA) equipped with a quaternary pump, an autosampler, and a photodiode array detector (DAD), using a Zorbax-XDB $\mathrm{C}_{18}(150 \times 4.6 \mathrm{~mm}, 5 \mu \mathrm{m})$ reverse phase column (Hewlett-Packard, Newport, USA), a methanol/water (40:60, $\mathrm{vol} / \mathrm{vol}$ ) solvent system, a flow rate of 1 $\mathrm{ml} / \mathrm{min}$, and 215-nm detection. Preparative LC was performed on a PrepLC 500A system (Waters, Milford, USA) using a 5.7 $\times 30 \mathrm{~cm}$ column packed with 15-20 $\mu \mathrm{m}$ Vydac $\mathrm{C}_{18}$ (Vydac, Hesperia, USA). The flow rate throughout was $7.5 \mathrm{ml} / \mathrm{min}$, and subfractions were collected under a 215$\mathrm{nm}$ detector. These subfractions were tested by leaf necrosis assay, and a bioactive compound designated as SS-toxin was further purified by LC and chosen for further analysis. To prepare a dosageresponse curve for SS-toxin, an aliquot of $10 \mu \mathrm{l}$ from $0.1,1,11,22,44,88,176,352$, or $704 \mu \mathrm{g} / \mathrm{ml}$ dilutions of SS-toxin was applied to each wound site on leaves of susceptible and resistant cultivars in the leaf necrosis assay.

Effect of SS-toxin on root growth, shoot elongation, and mitotic activity. Seeds of cv. Changbanpo were incubated in petri dishes on moistened filter paper at room temperature $\left(25^{\circ} \mathrm{C}\right)$ for $48 \mathrm{~h}$. Germinated seedlings were placed on filter paper saturated with a $10-\mathrm{ml}$ SS-toxin solution at $0,11,22,44,88,176,352$, or $704 \mu \mathrm{g} / \mathrm{ml}$ in 9-cm-diameter petri dishes (15 per plate replicated three times). The dishes were incubated at $25^{\circ} \mathrm{C}$ with a $12-\mathrm{h}$ photoperiod. Root and shoot lengths were measured after 5 days of incubation. To assess the effects of SS-toxin on mitotic activity, germinated garlic cloves (cv. Changbanpo) with 3- to 4-cm-long roots were placed in a plastic dish containing $10 \mathrm{ml}$ of SS-toxin solution at concentrations of $0,11,22,44$, $88,176,352$, or $704 \mu \mathrm{g} / \mathrm{ml}$, using the methods of Jiang et al. (13) for fixation, digestion, and staining. Up to 1,000 cells per slide for each treatment were viewed to evaluate mitotic activity by microscopy. Mitotic index (\%) was evaluated and is defined as the ratio between the number of cells undergoing mitosis and the total number of cells. Each treatment was repeated three times.

Chlorophyll content reduction. Young leaves (20 days old) of cv. Changbanpo were harvested for detached leaf assays with SS-toxin and subsequent chlorophyll content analyses. The abaxial surfaces were superficially wounded as described above. An aliquot of $30 \mu \mathrm{l}$ of SS-toxin solution $(0,10,50,100$, or $200 \mu \mathrm{g} / \mathrm{ml})$ was applied to each wound site. All treatments were then incubated at $25^{\circ} \mathrm{C}$ for 3 days in a moist chamber. The chlorophyll content of garlic leaves was determined according to the method of Arnon (2). A sample (0.5 g) of leaf tissue was placed into a tube with $15 \mathrm{ml}$ of $80 \%$ acetone. After extraction for 2 days, extracts were topped off with $80 \%$ acetone to make up the original $15-\mathrm{ml}$ volume. For each extract, the absorbances at 645,652 , and $663 \mathrm{~nm}$ were recorded. Each experiment was repeated three times. Chlorophyll contents were calculated using the following formulae (2):

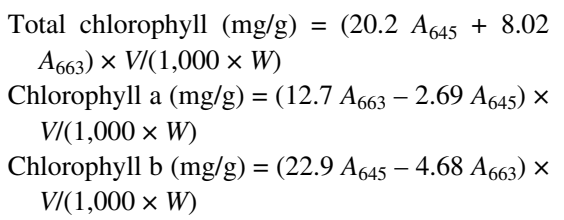

Where $V=$ volume assessed, and $W=$ weight of sample.

Chlorophyll content reduction $(\%)=\left(C_{0}-C\right) \times$ $100 / C_{0}$

Where $C_{0}=$ amount of chlorophyll in control, and $C=$ amount of chlorophyll after 3 days toxin treatment.

Transmission electron microscopy. A concentration of $200 \mu \mathrm{g} / \mathrm{ml} \mathrm{SS-toxin} \mathrm{solu-}$ tion was used for treating susceptible (cv. Changbanpo) and resistant (cv. Qingganruanye) garlic leaves following the leaf necrosis assay described above. Treated leaves were then incubated at $25^{\circ} \mathrm{C}$ for 2 , 6,12 , or $24 \mathrm{~h}$ in a moist chamber. Following previously described procedures (20), tissues of toxin or control treated sites were cut into small pieces and prefixed with $2.5 \%$ glutaraldehyde in $0.1 \mathrm{M}$ phosphate buffer ( $\mathrm{pH} 7.2)$ for $6 \mathrm{~h}$ at $4^{\circ} \mathrm{C}$. After rinsing with the phosphate buffer several times, leaf tissues were postfixed with $1.5 \%$ osmium tetroxide in the phosphate buffer for $2 \mathrm{~h}$ at $4^{\circ} \mathrm{C}$. The sections were then dehydrated with ethanol and embedded in Epon-812 resin (Shell chemicals, Houston, USA). The ultrathin sections were cut and stained with $2 \%$ uranyl acetate and lead citrate, and observed under a Hitachi H-7000 electron microscopy (Hitachi, Tokyo, Japan).

Data analysis. The data were subjected to analysis of variance (ANOVA), and when significant treatment differences were found, means were compared by the test of least significant difference (LSD, $P$ $<0.05)$. A dosage response curve was prepared to demonstrate the relationship between phytotoxin concentration and necrotic lesion development. The effective dose causing $50 \%$ inhibition of root or shoot growth $\left(\mathrm{EC}_{50}\right)$ was then determined by calculating the percent inhibition by each toxin concentration [ 1 - (mean extension length of toxin-treated roots or shoots divided by mean extension length of watertreated roots or shoots) $] \times 100$, and subjecting these data to probit analysis (8) using DPS (version 3.01) software. Probit transformation serves to straighten the 
dosage-response curve and allows more accurate estimation of $\mathrm{EC}_{50}$ values compared to untransformed data (21). Analysis of variance of chlorophyll content reduction (\%) was performed using a two-factor completely randomized design.

\section{RESULTS}

Toxin production and preliminary characterization in vitro. Culture filtrates of S. solani grown on seven different liquid media could induce leaf necrosis. However, filtrate from 21-day-old PSB cultures producing an average lesion size of 66 $\mathrm{mm}^{2}$, was significantly more toxic to garlic leaves than filtrates from other media (PDB, KB, Czapek, Richard, $\mathrm{V}_{8}$, and Fries) which caused lesion sizes of 41,13 , $9,7,5$, and $3 \mathrm{~mm}^{2}$, respectively $(P<0.05)$. Filtrates from noninoculated media caused no lesions on tested garlic leaves. Hence, all subsequent tests were conducted with PSB filtrates.

Preliminary characterization of toxic activity in vitro was done before toxin isolation. No toxicity was detected in the precipitates, which came after the addition of methanol or acetone (Table 1). When the crude toxin was treated with active carbon, the toxicity could be detected only in the solution, demonstrating that the toxin was not absorbed by active carbon (Table 1). The toxic components were found only in the solvent fraction after the culture filtrates were partitioned with ethyl acetate or chloroform, and in the water fraction after partitioning with petroleum ether, cyclohexane, carbon tetrachloride, or ether. After partitioning with benzene, the toxins were detected both in water and in solvent fractions (Table 1). Since the ethyl acetate extract showed significantly higher toxicity than the one from chloroform $(P<0.05)$, the solvent ethyl acetate was chosen for extraction of the toxins from culture filtrate. The toxic activity in culture filtrates was stable even after incubation at $121^{\circ} \mathrm{C}$ for up to $30 \mathrm{~min}$, indicating that they were highly thermostable.

Isolation and purification of SS-toxin. To obtain a sufficient amount of the bioactive compound, mycelium of $S$. solani was grown in 2 liters of PSB for 21 days. Extraction with ethyl acetate gave a yellowbrown residue $(1.3 \mathrm{~g})$ with high phytotoxic activity after being dissolved in sterile distilled water and used in leaf necrosis assay. On preparative TLC plates, toxicity was only detected at the starting point after the separation of crude extract (dissolved in methanol) under five solvent systems, such as normal butanol/acetone/water (6:1:3, vol/vol/vol), chloroform/methanol/ water $(6: 3: 1, \mathrm{vol} / \mathrm{vol} / \mathrm{vol})$, chloroform/water/ formic acid $(6: 3: 1, \mathrm{vol} / \mathrm{vol} / \mathrm{vol})$, normal butanol/acetic acid/water (8:2:1, vol/vol/ vol), and normal butanol/cyclohexane/ methanol (15:5:1, vol/vol/vol). Toxicity of the main toxic compound was located at mean retention factor $(\mathrm{Rf})$ value of 0.3
Table 1. Phytotoxicity on leaves of garlic cv. Changbanpo of crude toxin isolated with various treatments from culture filtrates of Stemphylium solani after 3 days in a leaf necrosis assay

\begin{tabular}{|c|c|c|c|}
\hline Experiment & Treatment & Fraction & Lesion area $\left(\mathrm{mm}^{2}\right)^{y}$ \\
\hline \multirow[t]{5}{*}{1} & Methanol & Water fraction & $19.8 \mathrm{a}$ \\
\hline & & Precipitate & $0 \mathrm{~b}$ \\
\hline & Acetone & Water fraction & $18.0 \mathrm{a}$ \\
\hline & & Precipitate & $0 \mathrm{~b}$ \\
\hline & Culture filtrate $(\text { control })^{\mathrm{z}}$ & & $20.3 \mathrm{a}$ \\
\hline \multirow[t]{3}{*}{2} & Active carbon & Nonadsorbed fraction & $18.6 \mathrm{a}$ \\
\hline & & Adsorbed fraction & $0 \mathrm{~b}$ \\
\hline & Culture filtrate (control) & & $18.6 \mathrm{a}$ \\
\hline \multirow[t]{15}{*}{3} & Petroleum ether & Solvent fraction & $0 \mathrm{~d}$ \\
\hline & & Water fraction & $2.3 \mathrm{c}$ \\
\hline & Cyclohexane & Solvent fraction & $0 \mathrm{~d}$ \\
\hline & & Water fraction & $2.5 \mathrm{c}$ \\
\hline & Carbon tetrachloride & Solvent fraction & $0 \mathrm{~d}$ \\
\hline & & Water fraction & $1.8 \mathrm{c}$ \\
\hline & Ether & Solvent fraction & $0 \mathrm{~d}$ \\
\hline & & Water fraction & $2.5 \mathrm{c}$ \\
\hline & Benzene & Solvent fraction & $1.3 \mathrm{~cd}$ \\
\hline & & Water fraction & $2.5 \mathrm{c}$ \\
\hline & Ethyl acetate & Solvent fraction & $7.7 \mathrm{~b}$ \\
\hline & & Water fraction & $0 \mathrm{~d}$ \\
\hline & Chloroform & Solvent fraction & $2.8 \mathrm{c}$ \\
\hline & & Water fraction & $0 \mathrm{~d}$ \\
\hline & Culture filtrate (control) & & $10.8 \mathrm{a}$ \\
\hline
\end{tabular}

${ }^{y}$ Means within a column for each experiment followed by a letter in common are not significantly different at $P<0.05$ in a least significant difference test.

${ }^{\text {z }}$ Culture filtrates from $S$. solani cultures grown for 21 days in potato sucrose broth medium served as controls.

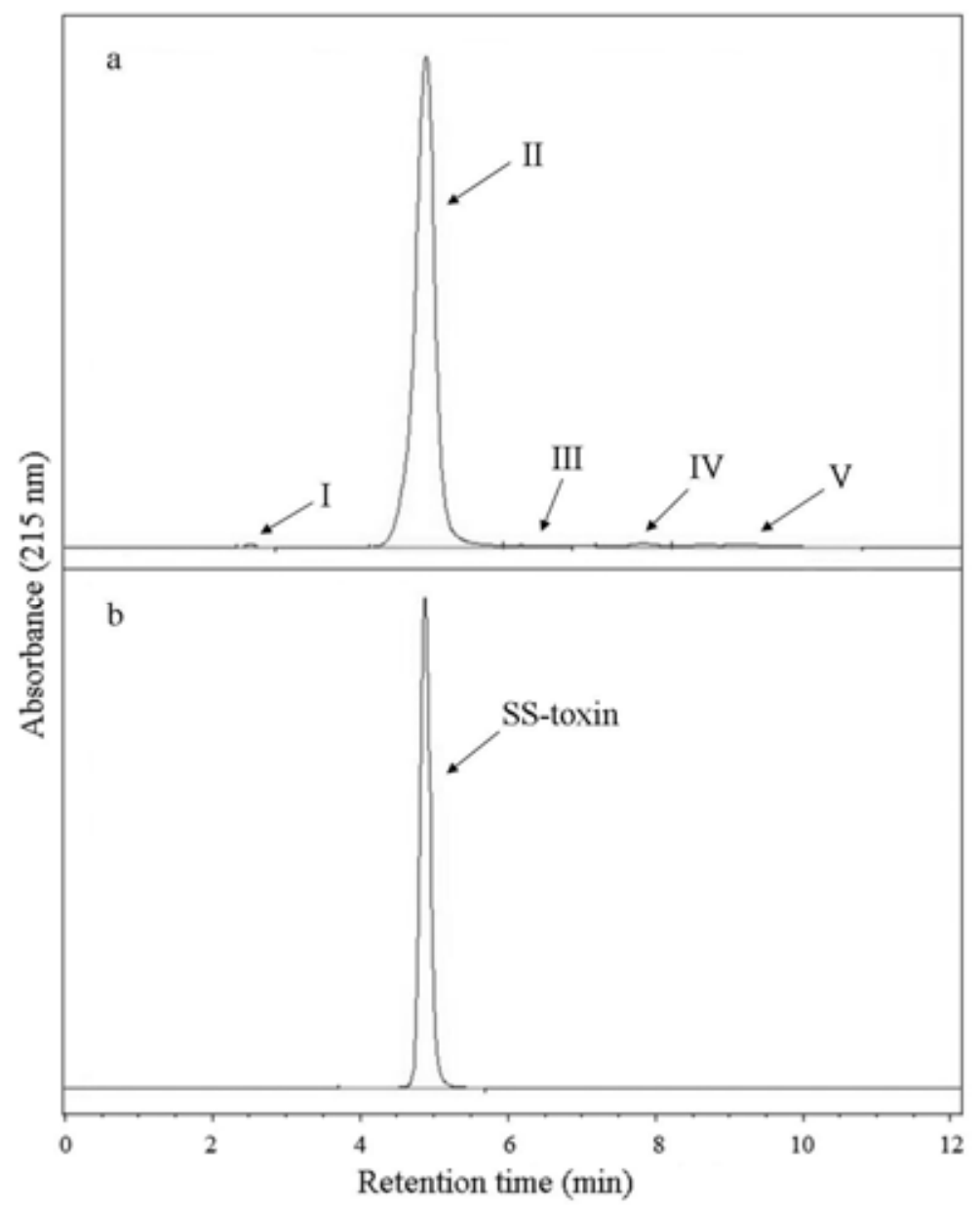

Fig. 1. High-performance liquid chromatography (HPLC) elution profile of crude toxin in methanol obtained from a, thin-layer chromatograph (TLC) plates and $\mathbf{b}$, purified SS-toxin. HPLC was carried out with a Zorbax-XDB $\mathrm{C}_{18}$ reverse phase column, a methanol/water (40:60, vol/vol, in $12 \mathrm{~min}$ ) solvent system, a flow rate of $1 \mathrm{ml}$ per min, and 215-nm detection. I, II, III, IV, and V indicate the five detected fractions in crude toxin. 
with ethyl acetate/petroleum ether (2:1, $\mathrm{vol} / \mathrm{vol}), 0.3$ with ethyl acetate/hexane $(8: 1, \quad \mathrm{vol} / \mathrm{vol}), \quad 0.4$ with normal butanol/hexane/methanol (15:5:1, vol/vol/ vol), and 0.4 with ethyl acetate/petroleum ether/methanol (4:1:0.35, vol/vol/vol). The greatest number of bands (13 bands) was obtained with the solvent system ethyl

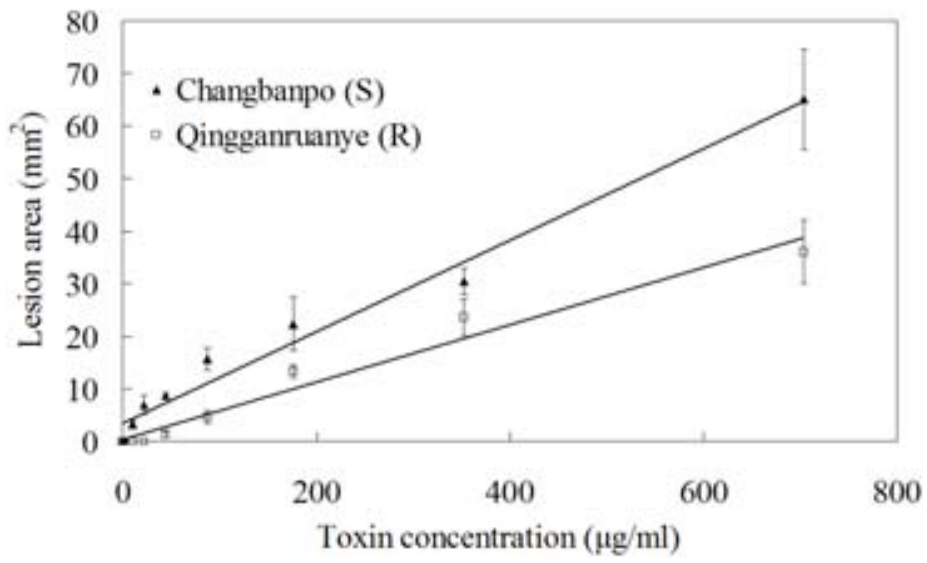

Fig. 2. Relationship between concentration of SS-toxin and size of necrotic lesions on leaves of garlic cv. Changbanpo (susceptible) or Qingganruanye (resistant). Necrotic lesions were measured $72 \mathrm{~h}$ after treatment with $10 \mu \mathrm{l}$ of SS-toxin at different concentrations. Vertical bars indicate standard error of measurements for three sets of experiments. Regression lines for susceptible and resistant cultivars are, respectively, as follows: $y_{s}=0.087 x_{s}+3.389, R^{2}=0.977, P<0.05$, and $y_{r}=0.055 x_{r}+0.297, R^{2}=$ $0.969, P<0.05$.

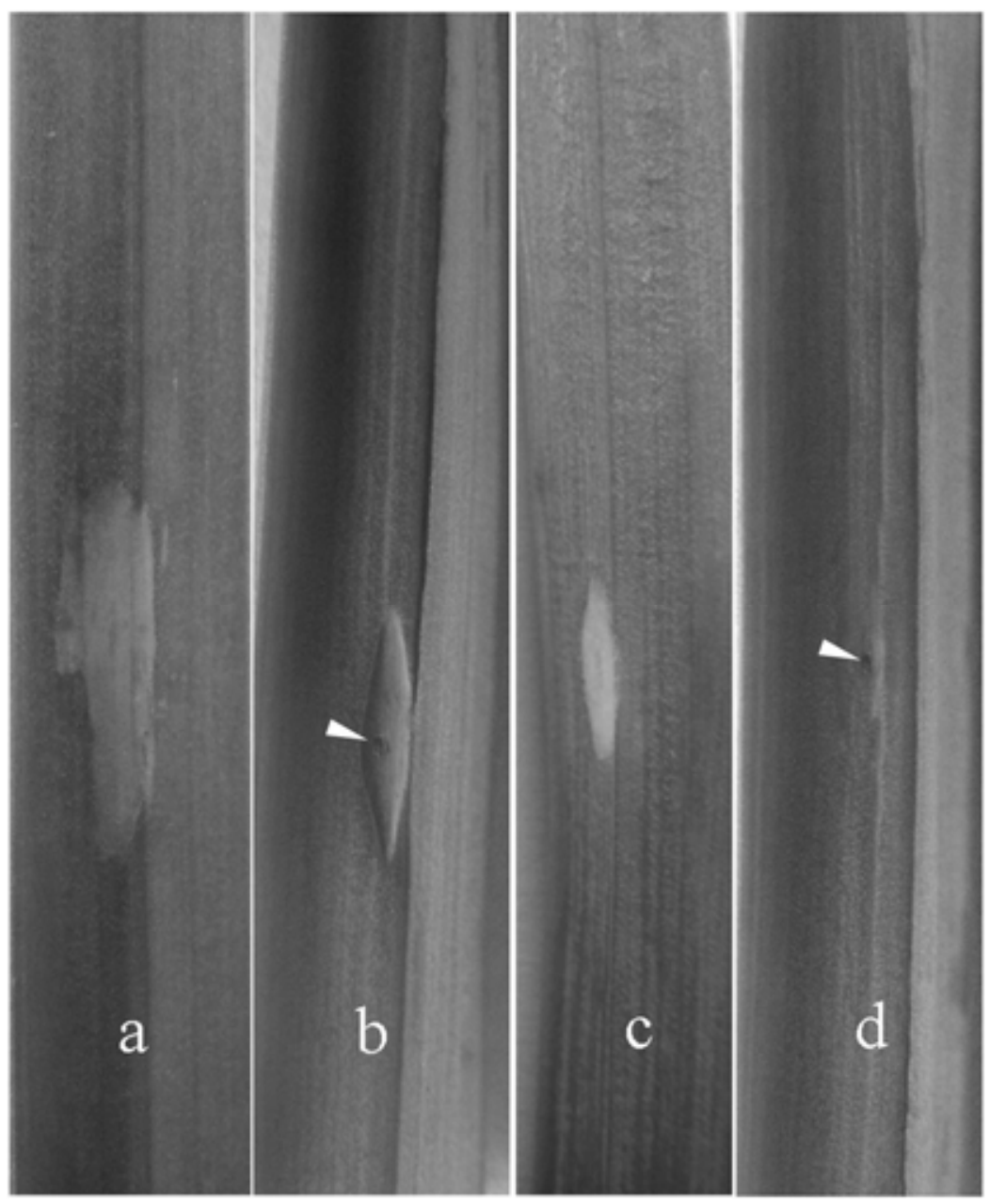

Fig. 3. Necrotic lesions produced by Stemphylium solani and SS-toxin on wounded garlic leaves of cv. Changbanpo (susceptible) or cv. Qingganruanye (resistant). These were inoculated with fungal plugs 6 $\mathrm{mm}$ in diameter or treated with $10-\mu \mathrm{l}$ droplets of $44 \mu \mathrm{g} / \mathrm{ml}$ of SS-toxin. All treated leaves were incubated at $25^{\circ} \mathrm{C}$ for 3 days. Arrows indicate points of wounding and toxin placement. a, Susceptible cultivar inoculated with fungus. b, Susceptible cultivar treated with SS-toxin. c, Resistant cultivar inoculated with fungus. d, Resistant cultivar treated with SS-toxin.

acetate/petroleum ether/methanol (4:1:0.35, $\mathrm{vol} / \mathrm{vol} / \mathrm{vol}$ ), and this optimal solvent system was used for preparative TLC. The first, second, third, fourth, and seventh fractions among the total 13 fractions produced average lesion sizes of $8,12,9,110$, and $4 \mathrm{~mm}^{2}$, respectively, in the leaf necrosis assay, whereas no lesions were produced by other fractions including the start point. The fourth fraction $(220 \mathrm{mg})$ was found to be the one with the highest activity, and this fraction was then subjected to analytical HPLC with a methanol/water (40:60, vol/vol) solvent system to produce five subfractions: I (retention time [Rt] 0 $3.0 \mathrm{~min}$ ), II (Rt 3.0-5.8 min), III (Rt 5.87.1 min), IV (Rt 7.1-8.2 min), and V (Rt 8.2-12.0 min) (Fig. 1). Only subfraction II showed toxicity on garlic leaves. Hence, subfraction II was purified further with preparative LC, yielding a single peak at an Rt of $4.8 \mathrm{~min}$, as shown by HPLC analysis using a methanol/water (40:60, $\mathrm{vol} / \mathrm{vol})$ solvent system, a flow rate of 1 $\mathrm{ml} / \mathrm{min}$, and 215-nm detection (Fig. 1). The purified phytotoxin, named SS-toxin (50 mg from 2 liters of culture filtrate), appeared as red-brown crystals after evaporation to dryness.

Dosage-response curve. The development of necrotic lesions on susceptible cv. Changbanpo and resistant cv. Qingganruanye was positively related to SS-toxin concentration (Fig. 2). The necrosis induced by SS-toxin was similar to the symptoms caused by S. solani (Fig. 3). Necrotic lesions induced by SS-toxin were significantly $(\mathrm{P}<0.05)$ larger on the susceptible cultivar than on the resistant cultivar. Visible symptoms on the susceptible cultivar could be observed with a toxin concentration of $11 \mu \mathrm{g} / \mathrm{ml}$ by $72 \mathrm{~h}$ after treatment, while a minimum toxin concentration of $44 \mu \mathrm{g} / \mathrm{ml}$ was needed to cause symptoms on the resistant cultivar by $72 \mathrm{~h}$ after treatment (Fig. 2). SS-toxin at a concentration of $200 \mu \mathrm{g} / \mathrm{ml}$ caused visible necrosis of susceptible leaves $12 \mathrm{~h}$ after toxin treatment, while on the leaves of resistant cv. Qingganruanye, necrosis was first observed $24 \mathrm{~h}$ after treatment.

Effect of SS-toxin on root growth, shoot elongation, and mitotic activity. All concentrations of SS-toxin could reduce root and shoot growth of garlic cv. Changbanpo except for $11 \mu \mathrm{g} / \mathrm{ml}$ (Table 2, Fig. 4). Root growth was more susceptible to SS-toxin than shoot growth, and the $\mathrm{EC}_{50}$ values were 64.9 and $178.5 \mu \mathrm{g} / \mathrm{ml}$, respectively. After $24 \mathrm{~h}$ exposure to 22 $\mu \mathrm{g} / \mathrm{ml}$ or above of SS-toxin, the numbers of actively dividing cell root tips were significantly decreased $(P<0.05$, Table 2$)$, but no abnormal mitotic organization was observed in these cells.

Chlorophyll content reduction. Chlorophyll content reduction by the SS-toxin was detected at all tested concentrations in susceptible cv. Changbanpo (Table 3). Concentrations of 50,100 , and $200 \mu \mathrm{g} / \mathrm{ml}$ of SS- 
toxin were found to cause significant reductions in chlorophyll. The reductions in total chlorophyll and chlorophyll a and $\mathrm{b}$ were $68.2,63.1$, and $73.8 \%$, respectively, at the highest concentration tested (200 $\mu \mathrm{g} / \mathrm{ml})$.

Transmission electron microscopy. The mesophyll cells of susceptible cv. Changbanpo and resistant cv. Qingganruanye treated with $200 \mu \mathrm{g} / \mathrm{ml} \mathrm{SS-toxin} \mathrm{or}$ with water were observed by electron microscopy (Fig. 5). At this toxin concentration, macroscopically visible necrosis was found on the susceptible cultivar after $12 \mathrm{~h}$ and on the resistant cultivar after $24 \mathrm{~h}$. With water treatment alone, no changes in leaf cells or organelles of either cultivar were observed up to $24 \mathrm{~h}$ (Fig. 5a and i).

In leaf cells of the susceptible cultivar, the earliest toxin-induced ultrastructural changes were detected $2 \mathrm{~h}$ after toxin treatment in the plasma membranes and cell walls (Fig. 5b), and these modifications became more severe and more frequent up to $24 \mathrm{~h}$ of toxin exposure (Fig. 5h). Abundant amorphous materials were found between degraded cell walls by $12 \mathrm{~h}$ after treatment with the toxin of the susceptible cultivar (Fig. 5e). The number of mitochondrial cristae was reduced in leaves of the susceptible cultivar by $6 \mathrm{~h}$ after treatment with the toxin (Fig. 5c). Disordered chloroplast lamellae, swollen chloroplasts, and disrupted nuclear membranes appeared after $12 \mathrm{~h}$ of exposure to the toxin for the susceptible cultivar (Fig. $5 \mathrm{~d}$ and $\mathrm{f}$ ). No apparent change of rough endoplasmic reticulum was observed even after $24 \mathrm{~h}$ (Fig. $5 \mathrm{~g}$ ).

In leaf cells of the resistant cultivar, the earliest effects (plasma-membrane invagination and cell wall changes) were detected $12 \mathrm{~h}$ after toxin treatment (Fig. 5j). The numbers of mitochondrial cristae were reduced by $24 \mathrm{~h}$ (Fig. 5k). Other organelles including chloroplast, nuclear membrane, and rough endoplasmic reticulum were seemingly not affected in leaf cells of the resistant cultivar during the first $24 \mathrm{~h}$ of exposure (Fig. 5k and 1).

\section{DISCUSSION}

One of the problems in studying phytotoxins produced by fungi is that they are often produced and released in artificial medium in very low amounts, causing difficulties in purification and identification of compounds $(24,25)$. In this study, the use of PSB and the growth of $S$. solani in shake culture for 21 days yielded more than $600 \mathrm{mg} / \mathrm{liter}$ of crude toxins. When the fungus was incubated for more than 30 days, there was a reduction in the overall toxic activity, which is likely due to the

Table 2. Effect of SS-toxin of Stemphylium solani on root growth, shoot elongation, and mitotic activity of cloves of garlic cv. Changbanpo after 5 days at $25^{\circ} \mathrm{C}$ with $12 \mathrm{~h} / 12 \mathrm{~h} \mathrm{light/darkness}$

\begin{tabular}{lccc}
\hline $\begin{array}{l}\text { Toxin concentration } \\
(\boldsymbol{\mu g} / \mathbf{m l})\end{array}$ & $\begin{array}{c}\text { Root growth } \\
\text { inhibition } \mathbf{( \% )}\end{array}$ & $\begin{array}{c}\text { Shoot growth } \\
\text { inhibition }^{\mathbf{y}}(\boldsymbol{\%})\end{array}$ & ${\text { Mitotic } \text { index }^{\mathbf{z}}(\boldsymbol{\%})}$ \\
\hline 704 & $100.0 \mathrm{a}$ & $81.3 \mathrm{a}$ & $2.0 \mathrm{~d}$ \\
352 & $100.0 \mathrm{a}$ & $68.3 \mathrm{~b}$ & $5.2 \mathrm{~d}$ \\
176 & $100.0 \mathrm{a}$ & $50.3 \mathrm{c}$ & $4.3 \mathrm{~d}$ \\
88 & $80.3 \mathrm{~b}$ & $33.3 \mathrm{~d}$ & $30.8 \mathrm{c}$ \\
44 & $13.7 \mathrm{c}$ & $15.3 \mathrm{e}$ & $62.5 \mathrm{~b}$ \\
22 & $5.0 \mathrm{~d}$ & $5.0 \mathrm{f}$ & $73.1 \mathrm{~b}$ \\
11 & $0 \mathrm{~d}$ & $0 \mathrm{~g}$ & $81.5 \mathrm{a}$ \\
0 & $0 \mathrm{~d}$ & $0 \mathrm{~g}$ & $83.2 \mathrm{a}$ \\
$\mathrm{EC}_{50}$ & $64.9 \mu \mathrm{g} / \mathrm{ml}$ & $178.5 \mu \mathrm{g} / \mathrm{ml}$ & \\
\hline
\end{tabular}

${ }^{y}$ Mean extension lengths of water-treated roots and shoots were $26.0 \pm 8.5$ and $43.8 \pm 4.7 \mathrm{~mm}$, respectively. Means within a column followed by a letter in common are not significantly different at $P<$ 0.05 in a least significant difference test.

${ }^{\mathrm{z}}$ Mitotic index $(\%)$ is defined as ratio between number of cells in mitosis and total number of cells.

Table 3. Reduction in chlorophyll content of 20-day-old leaves of garlic cv. Changbanpo 3 days after treatment with various concentrations of SS-toxin of Stemphylium solani

\begin{tabular}{cccc}
\hline \multirow{2}{*}{$\begin{array}{l}\text { Toxin concentration } \\
(\boldsymbol{\mu g} / \mathbf{m l})\end{array}$} & \multicolumn{2}{c}{ Percent chlorophyll content reduction $(\boldsymbol{\%})^{\mathbf{z}}$} \\
\cline { 2 - 4 } & Total chlorophyll & Chlorophyll a & Chlorophyll b \\
\hline 200 & $68.2 \mathrm{ab}$ & $63.1 \mathrm{abc}$ & $73.8 \mathrm{a}$ \\
100 & $62.3 \mathrm{bc}$ & $56.3 \mathrm{c}$ & $68.7 \mathrm{ab}$ \\
50 & $28.3 \mathrm{~d}$ & $27.6 \mathrm{~d}$ & $28.7 \mathrm{~d}$ \\
10 & $10.6 \mathrm{ef}$ & $11.5 \mathrm{e}$ & $9.6 \mathrm{ef}$ \\
0 & $0 \mathrm{f}$ & $0 \mathrm{f}$ & $0 \mathrm{f}$ \\
\hline
\end{tabular}

${ }^{\mathrm{z}}$ Mean total chlorophyll, chlorophyll $\mathrm{a}$, and chlorophyll $\mathrm{b}$ were $0.9 \pm 0.1,0.5 \pm 0.1$, and $0.4 \pm 0.1$ $\mathrm{mg} / \mathrm{g} \mathrm{FW}$, respectively. Analysis of variance was performed using a two-factor, completely randomized design. Means followed by a letter in common are not significantly different at $P<0.05$ in a least significant difference test.

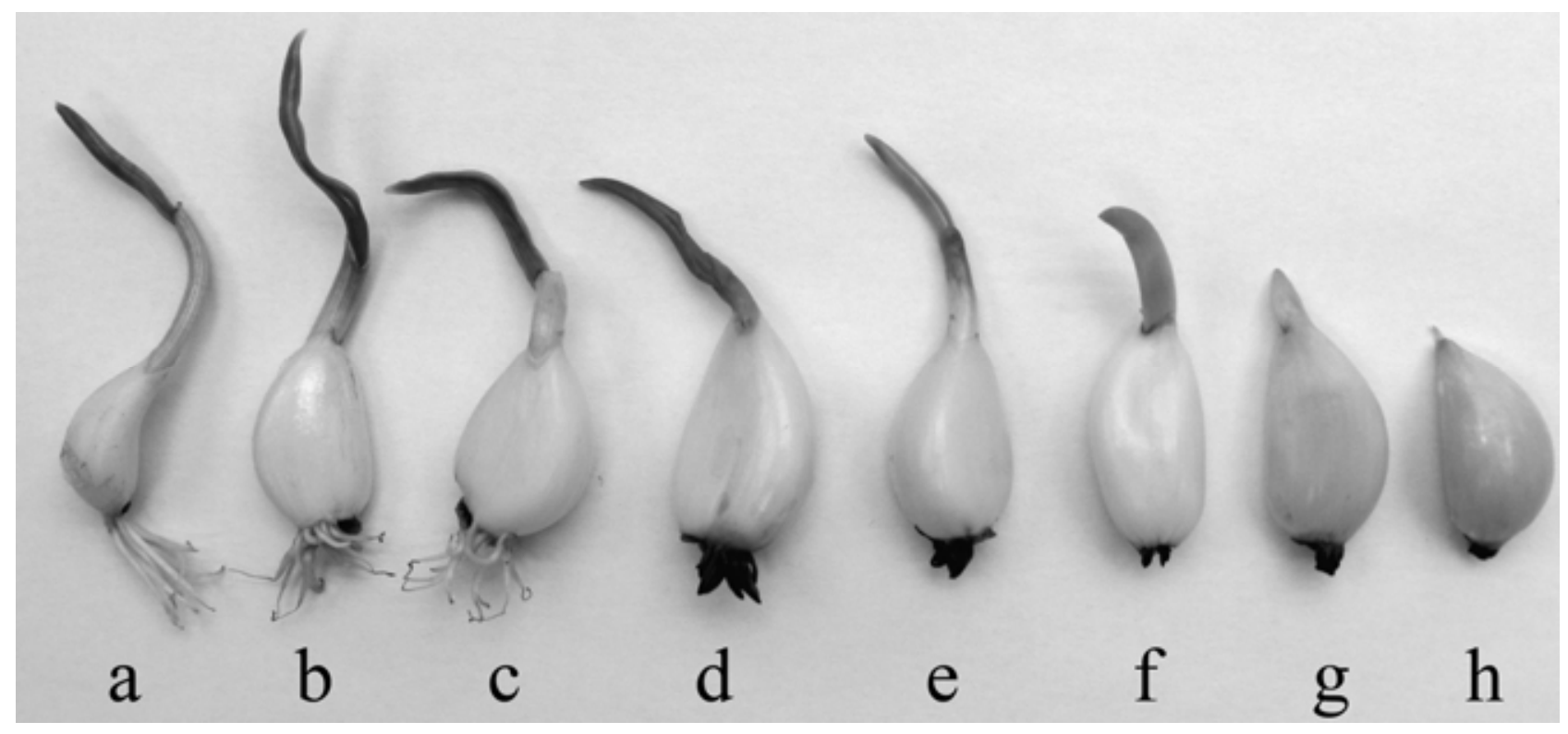

Fig. 4. Inhibition of garlic root and shoot growth by SS-toxin produced by Stemphylium solani after 5 days. Newly germinated garlic cloves (cv. Changbanpo) were treated with $10 \mathrm{ml}$ of SS-toxin solution at $\mathbf{a}, 0, \mathbf{b}, 11, \mathbf{c}, 22, \mathbf{d}, 44, \mathbf{e}, 88, \mathbf{f}, 176, \mathbf{g}, 352$, or h, $704 \mu \mathrm{g} / \mathrm{ml}$. 
instability or degradation of the toxin in culture medium (unpublished data).

SS-toxin was heat stable since culture filtrate still showed high toxicity after exposure up to $121^{\circ} \mathrm{C}$ for $30 \mathrm{~min}$. Solvent extraction to recover organic compounds with novel activity has been considered as one of the most effective methods to iso-
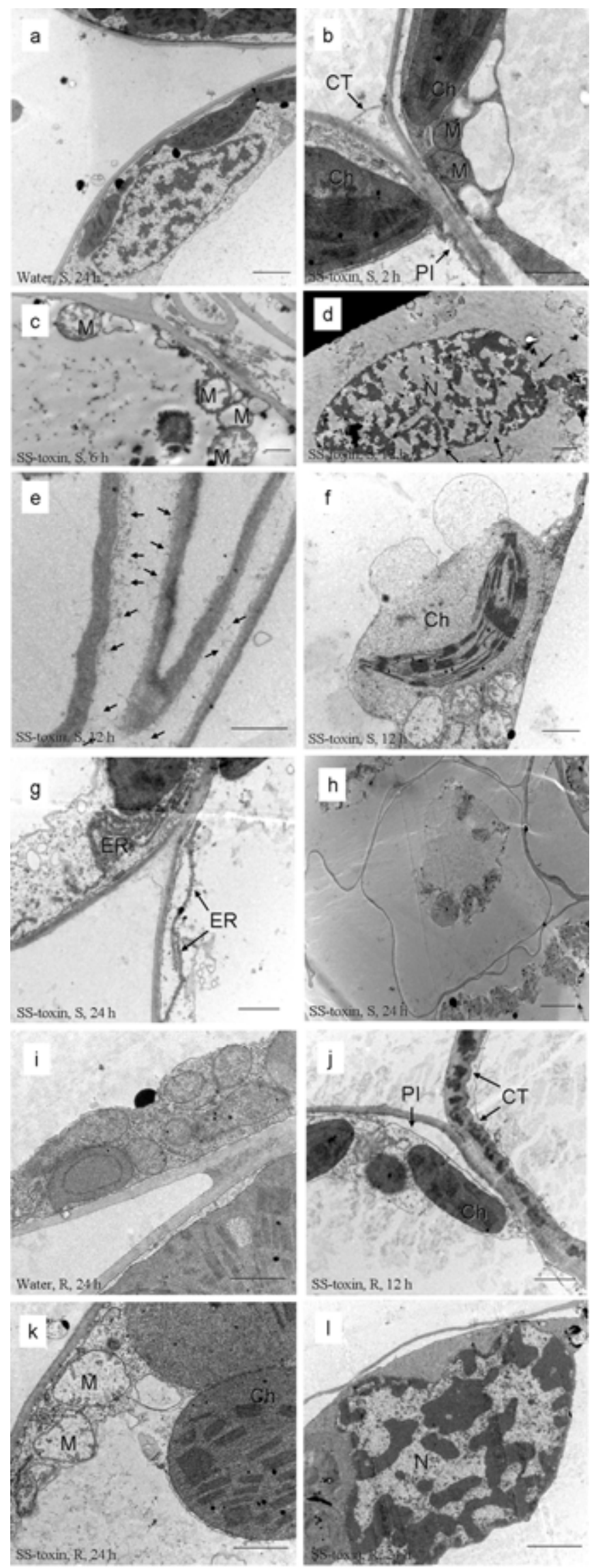

late phytotoxins from other fungal metabolites (27). We used ethyl acetate to extract the SS-toxin from culture filtrate. Variable phytotoxicity of different batches of culture filtrates was observed in this study, and this might be related to the age of cultures, since toxin production of $S$. solani isolates was reduced after transferring for several generations (29).

Several phytotoxic components were detected in culture filtrates in TLC and HPLC analysis. However, only the major phytotoxin, SS-toxin, which was the most phytotoxic compound observed in the culture filtrate, was purified in this study by a combination of two chromatography steps after extraction with ethyl acetate. Although the chemical structures of the phytotoxins produced by several species of Stemphylium are known, the physical characteristics of the SS-toxin differ from previously described phytotoxins produced by other species of Stemphylium. For instance, the color of the crystals was red-brown, while others are reported as white or yellow (1). Preliminary characterization has revealed that SStoxin is a quinone compound containing phenolic hydroxyl groups (30). Full structural characterization and identification of SS-toxin is currently in progress.

Fig. 5. Ultrastructure of leaf mesophyll cells of garlic cv. Changbanpo (susceptible) and Qingganruanye (resistant) treated with SS-toxin (30$\mu \mathrm{l}$ droplets of $200 \mu \mathrm{g} / \mathrm{ml}$ of toxin) or water. a, Ultrastructure of leaf mesophyll cells of susceptible Changbanpo treated with water for $24 \mathrm{~h}$. Bar $=2 \mu \mathrm{m}$. b, Plasma-membrane invaginations (PI) and cell-wall transformation (CT) in susceptible Changbanpo leaf treated with SS-toxin for $2 \mathrm{~h}$. No structural changes of mitochondria (M) and chloroplasts $(\mathrm{Ch})$ were observed. $\mathrm{Bar}=$ $1 \mu \mathrm{m}$. c, Disappearance of some mitochondrial cristae in susceptible Changbanpo leaf treated with SS-toxin for $6 \mathrm{~h}$. Bar $=1 \mu \mathrm{m}$. d, Disrupted nuclear $(\mathrm{N})$ membrane found in susceptible Changbanpo leaf treated with SS-toxin for $12 \mathrm{~h}$. Bar $=2 \mu \mathrm{m}$. e, Typical cell-wall transformation in susceptible Changbanpo leaf treated with SStoxin for $12 \mathrm{~h}$. Many amorphous materials (AM) were also observed between dividing cell walls. Bar $=1 \mu \mathrm{m}$. f, Disordered chloroplast lamellae and swollen chloroplast in susceptible Changbanpo leaf treated with SS-toxin for $12 \mathrm{~h}$. Bar = $1 \mu \mathrm{m}$. g, No apparent changes of rough endoplasmic reticulum (ER) in susceptible Changbanpo leaf treated with SS-toxin for $24 \mathrm{~h}$. Bar = $1 \mu \mathrm{m}$. h, Severe transformation of cells in susceptible Changbanpo leaf treated with SS-toxin for $24 \mathrm{~h}$. Bar $=5 \mu \mathrm{m}$. i, Ultrastructure of mesophyll cells of resistant Qingganruanye leaf treated with water for $24 \mathrm{~h}$. Bar $=1 \mu \mathrm{m}$. j, Plasma-membrane invaginations and cell-wall transformation in resistant Qingganruanye leaf treated with SS-toxin for $12 \mathrm{~h}$. No other ultrastructural changes were observed in the cells. Bar $=1 \mu \mathrm{m}$. k, Swelling and disappearance of mitochondrial cristae in resistant Qingganruanye leaf treated with SS-toxin for $24 \mathrm{~h}$. Chloroplasts maintained original configuration. Bar $=1 \mu \mathrm{m}$. $\mathbf{l}$, Nuclear membrane in resistant Qingganruanye leaf treated with SS-toxin for $24 \mathrm{~h}$, showing an intact structure. $\mathrm{Bar}=2 \mu \mathrm{m}$. 
The activity of phytotoxins in symptom production on garlic leaves was further substantiated in dosage response curves, where increased concentrations of purified phytotoxin caused increased severity of symptoms. A high concentration of pure phytotoxin caused severe leaf blight symptoms similar to those produced by $S$. solani in the later stages of infection. This implies that SS-toxin may be involved in virulence of $S$. solani on garlic leaves. Garlic root and shoot elongation were both inhibited by SS-toxin, with root growth more sensitive to lower concentrations of SS-toxin. Moreover, we found that SS-toxin disrupted cell division of garlic root tips, but whether the activity is direct or indirect remains unknown. A phytotoxin, $\alpha, \beta$ dehydrocurvularin, produced by Curvularia eragrostidis, has also been reported to be involved in the inhibition of germination, seedling growth, and root-tip mitosis of the weed Digitaria sanguinalis (13). However, SS-toxin needs to be tested on other plants such as weeds to assess its potential as an herbicide.

Chlorosis and necrosis associated with leaf blight of garlic are mainly caused by the irreversible destruction of the photosynthetic tissue (chlorophyll a and b), which after degradation is incapable of capturing light for energy generation and formation of reducing power required in photochemical reactions of photosynthesis $(7,15)$. Our results showed that SS-toxin significantly reduced total chlorophyll and also chlorophyll a and b contents.

In the present study, the ultrastructural effects of SS-toxin were investigated in garlic leaf tissues from susceptible and resistant cultivars. The first observable SStoxin-induced changes appeared on the plasma membrane-cell wall association of susceptible leaf cells by $2 \mathrm{~h}$ of exposure. Structural damage of mitochondria, chloroplasts, and nuclear membranes of susceptible leaf cells were also found with prolonged toxin exposure. The SS-toxin might act to induce the flaccidity of plant tissues as a result of interference with cellular membrane systems. Preliminary data (unpublished) showed that the $\mathrm{H}^{+}$-ATPase and standard redox activities of plasma membranes, isolated from leaves of the susceptible cultivar and the resistant cultivar, were both inhibited in vitro by SS-toxin in a dose-dependent manner. The mode of action of SS-toxin, therefore, appeared to be compatible with the hypothesis that plasma-membrane and cell-wall disorders, caused directly or indirectly by SS-toxin, were key factors in early pathogenesis on garlic leaves, leading to pathogen access to host cells, and that SS-toxin could disrupt the structure of cellular organelles $(14,19)$. One well-documented case of phytotoxininduced membrane damage is SV-toxin of $S$. vesicarium; however, SV-toxin only caused plasma membrane modifications in susceptible pear tissues (20) and not in resistant ones. In this study, SS-toxin also induced some changes in a resistant garlic cultivar but at a much slower rate, and with higher threshold concentrations.

This is the first report of the purification of a phytotoxin produced by $S$. solani. The results of physiological studies indicated that the SS-toxin caused necrosis, visualized at the subcellular level by membrane disruption and organelle collapse. More intensive study of the ability of resistant garlic cultivars to withstand effects of the toxin, and on the vulnerability of susceptible garlic cultivars, may shed light on the mechanism of symptom development in infected plants at the macroscopic, cellular, and molecular levels.

\section{ACKNOWLEDGMENTS}

This work was supported by The Key Agricultural Research Project (2006AA201B06) of Hubei Province, China, and by the Ontario Ministry of Agriculture, Food and Rural Affairs, Ontario, Canada.

\section{LITERATURE CITED}

1. Andersen, B., Solfrizzo, M., and Visconti, A. 1995. Metabolite profiles of common Stemphylium species. Mycol. Res. 99:672-676.

2. Arnon, D. I. 1949. Copper enzymes in isolated chloroplasts. Polyphenoloxidase in Beta vulgaris. Plant Physiol. 24:1-15.

3. Arnone, A., Nasini, G., Merlini, L., and Assante, G. 1986. Secondary mould metabolites. Part 16. Stemphyltoxins, new reduced perylenequinone metabolites from Stemphylium botryosum var. Lactucum. J. Chem. Soc. Perk. Trans. 1:525-530.

4. Barash, I., Karr, A. L., and Strobel, G. A. 1975. Isolation and characterization of stemphylin, a chromone glucoside from Stemphylium botryosum. Plant Physiol. 55:646-651.

5. Barash, I., Manulis, S., Kashman, Y., Springer, J. P., Chen, M. H. M., Clardy, J., and Strobel, G. A. 1983. Crystallization and x-ray analysis of stemphyloxin I, a phytotoxin from Stemphylium botryosum. Science 220:1065-1066.

6. Barash, I., Pupkin, G., Netzer, D., and Kashman, Y. 1982. A novel enolic $\beta$-ketoaldehyde phytotoxin produced by Stemphylium botryosum f. sp. Lycopersici. Plant Physiol. 69:23-27.

7. Chauhan, R. S., Singh, B. M., and Develash, R. K. 1997. Effect of toxic compounds of Exserohilum turcicum on chlorophyll content, callus growth and cell viability of susceptible and resistant inbred lines of maize. J. Phytopathol. 145:435-440.

8. Finney, D. J. 1971. Probit Analysis, 3rd ed. Cambridge University Press, Cambridge, UK.

9. Grove, J. F. 1964. Metabolic products of Stemphylium radicinum. Part I. Radicinin. J. Chem. Soc. 3234.

10. Grove, J. F. 1971. Metabolic products of Stemphylium radicinum. IV. Minor products. J. Chem. Soc. 2261-2263.

11. Hansen, R. O. 1954. Stemphylone, a rootkilling substance from Stemphylium radicinum. Acta Chem. Scand. 8:1332-1334.

12. Huber, C. S. 1975. The structure of stemphone, a yellow fungal metabolite. Acta Crystallogr. Sect. B 31:108-113.

13. Jiang, S. J., Qiang, S., Zhu, Y. Z., and Dong, Y. F. 2008. Isolation and phytotoxicity of a metabolite from Curvularia eragrostidis and characterisation of its modes of action. Ann. Appl. Biol. 152:103-111.

14. Kohmoto, K., Otani, H., Kodama, M., and Nishimura, S. 1989. Host recognition: Can accessibility to fungal invasion be induced by host-specific toxins without necessitating ne- crotic cell death? Pages 250-273 in: Phytotoxins and Plant Pathogenesis. A. Graniti, R. D. Durbin, and A. Ballio, eds. Springer-Verlag, Berlin.

15. Kosuge, T. 1978. The capture and use of energy by diseased plants. Pages 86-113 in: Plant Disease VIII: How Plants Suffer from Disease. J. G. Horsfall and E. B. Cowling, eds. Academic Press, London.

16. Manulis, S., Kashman, Y., Netzer, D., and Barash, I. 1984. Phytotoxins from Stemphylium botryosum: Structural determination of stemphyloxin II, production in culture and interaction with iron. Phytochemistry 23:21932198.

17. Mehta, Y. R., and Brogin, R. L. 2000. Phytotoxicity of a culture filtrate produced by Stemphylium solani of cotton. Plant Dis. 84:838842.

18. Singh, P., Bugiani, R., Cavanni, P., Nakajima, H., Kodama, M., Otani, H., and Kohmoto, K. 1998. Purification, biological and chemical characterization of a host-specific SV-toxin from culture filtrates of Stemphylium vesicarium causing brown spot of European pears. Paper 1.8.23 in: Abstr. Proc. 7th Int. Congr. Plant Pathol.

19. Singh, P., Bugiani, R., Cavanni, P., Nakajima, H., Kodama, M., Otani, H., and Kohmoto, K. 1999. Purification and biological characterization of host-specific SV-toxins from Stemphylium vesicarium causing brown spot of European pear. Phytopathology 89:947-953.

20. Singh, P., Park, P., Bugiani, R., Cavanni, P., Nakajima, H., Kodama, M., Otani, H., and Kohmoto, K. 2000. Effects of host-selective SV-toxin from Stemphylium vesicarium, the cause of brown spot of European pear plants, on ultrastructure of leaf cells. J. Phytopathol. 148:87-93.

21. Sokal, R. R., and Rohlf, F. J. 1981. Biometry, the principles and practice of statistics in biological research. W. H. Freeman and Company, New York, USA.

22. Solfrizzo, M., Strange, R. N., Sabia, C., and Visconti, A. 1994. Production of a toxin stemphol by Stemphylium species. Nat. Toxins 2:14-18.

23. Starratt, A. N., and Stoessl, A. 1977. Synthesis of 3, 5-dihydroxy-2, 2-dimethylchroman-4-one and its implications for the structure of the phytotoxin stemphylin. Can. J. Chem. 55:2360-2362.

24. Strange, R. N. 2007. Phytotoxins produced by microbial plant pathogens. Nat. Prod. Rep. 24:127-144.

25. Strobel, G. A. 1982. Phytotoxins. Annu. Rev. Biochem. 51:309-333.

26. Vidhyasekaran, P., Ponmalar, T. R., Samiyappan, R., Velazhahan, R., Vimala, R., Ramanathan, A., Paranidharan, V., and Muthukrishnan, S. 1997. Host-specific toxin production by Rhizoctonia solani, the rice sheath blight pathogen. Phytopathology 87:1258-1263.

27. Vikrant, P., Verma, K. K., Rajak, R. C., and Pandey, A. K. 2006. Characterization of a phytotoxin from Phoma herbarum for management of Parthenium hysterophorus L. J. Phytopathol. 154:461-468.

28. Zheng, L., Huang, J. B., and Hsiang, T. 2008. First report of leaf blight of garlic (Allium sativum) caused by Stemphylium solani in China. Plant Pathol. 57:380.

29. Zheng, L., Lv, R. J., Hsiang, T., and Huang, J. B. 2009. Host range and phytotoxicity of Stemphylium solani, causing leaf blight of garlic (Allium sativum) in China. Eur. J. Plant Pathol. 124:21-30.

30. Zheng, L., Lv, R. J., Hsiang, T., Jiang, D. H., and Huang, J. B. 2008. Partial chemical characterization of the phytotoxin produced by Stemphylium solani. Page 61-62 in: Abstr. Proc. Microbial Toxin Congr. Chinese Soc. Microbiol. (in Chinese) 